\title{
Analisis Pengaruh Praktek Keselamatan dan Kesehatan Kerja terhadap Kinerja Karyawan dimediasi oleh Komitmen Organisasi
}

\author{
Shinta Pradita \\ Program Magister Manajemen, Universitas Internasional Batam \\ shintapradita25@gmail.com
}

\author{
Antony Sentoso* \\ Program Magister Manajemen, Universitas Internasional Batam \\ antony.sentoso@uib.ac.id
}

\begin{abstract}
This study aims to analyze the effect of occupational safety and health practices on employee performance mediated by work alienation and organizational commitment. This research was conducted on 2 companies engaged in the fabrication industry in the Batu Ampar Industrial Area. The data collection was carried out using the questionnaire method and the number of respondents from this study was 278 respondents. The data analysis method uses the SmartPLS 3.3 application. The results of the validity test of the four variables show the average variance extracted (AVE) value of more than 0.5 and the reliability test results of the four variables show the composite reliability value of more than 0.70 where based on the test results both are valid and reliable and meet the requirements of convergent validity. The results showed that there was a significant effect between occupational safety and health on employee performance mediated by organizational commitment, but there was an insignificant effect between occupational safety and health on employee performance mediated by work alienation
\end{abstract}

Keywords Occupational Safety and Health, Employee Performance, Work Alienation, Organizational Commitment.

\section{PENDAHULUAN}

Menurut Okezone (2019), Kondisi kesehatan dan keselamatan kerja di Indonesia secara umum tergolong rendah apabila dibandingkan dengan negara-negara Asia Tenggara lainnya seperti Singapura, Malaysia, Filipina, dan Thailand. Dengan begitu menggambarkan bahwa industri Indonesia masih sangat tidak berdaya saing di kancah Internasional karena rendahnya tingkat produktivitas tenaga kerja lndonesia. Peran kualitas tenaga kerja mempengaruhi kemajuan perusahaan atau menjadi kriteria penentu. Mengintegrasikan kesehatan dan keselamatan kerja untuk meningkatkan kinerja karyawan semakin diakui di seluruh dunia dan menjadi penting secara strategis seiring berjalannya waktu. Organisasi yang mengintegrasikan kesehatan dan keselamatan kerja dalam kebijakan mereka, membimbing manajemen dan karyawan dalam budaya tempat kerja yang positif yang pada akhirnya meningkatkan produktivitas dan profitabilitas bagi organisasi. Keselamatan dan kesehatan kerja merupakan suatu upaya dalam proses produksi baik dalam bidang jasa ataupun industri guna mencegah risiko kecelakaan dan juga penyakit akibat pekerjaan. (http://bppsdmk.kemkes.go.id).

Dalam UU No. 1 Tahun 1970 dijelaskan tujuan Keselamatan dan Kesehatan kerja yakni melakukan aktivitas kerja secara aman dan efisien mengikuti anjuran prosedur keamanan dan keselamatan serta menggunakan alat perlindungan diri sehingga dapat terhindar dari kemungkinan terjadinya kecelakaan ataupun sakit akibat kerja. Berikut inilah fungsi dan tujuan umum dari K3 perlu diterapkan di perusahaan: 1. Melindungi dan memelihara kesehatan dan keselamatan pekerja untuk meningkatkan efisiensi kerja.

2. Menjamin dan memelihara kesehatan dan keselamatan semua pekerja di tempat kerja.

3. Memastikan semua sumber daya produksi dipelihara dengan baik dan digunakan dengan cara yang aman dan efisien. 
Dari penjabaran di atas maka dapat disimpulkan bahwa penciptaan lingkungan kerja yang aman dan sehat bagi pekerja, perusahaan sebaiknya memperhatikan prosedur Keselamatan dan Kesehatan kerja yang dimilikinya secara kontinu untuk dapat mencegah ataupun mengurangi tingkat cedera ataupun penyakit akibat kerja yang terjadi di perusahaannya.

Adapun tujuan penelitian ini ialah:

1) Untuk mengetahui apakah terdapat pengaruh antara Kesehatan dan keselamatan kerja terhadap Kinerja karyawan.

2) Untuk mengetahui apakah terdapat pengaruh antara Kesehatan dan keselamatan kerja terhadap Keterasingan kerja.

3) Untuk mengetahui apakah terdapat pengaruh antara Kesehatan dan keselamatan kerja terhadap Komitmen organisasi.

4) Untuk mengetahui apakah terdapat pengaruh antara Keterasingan kerja terhadap Kinerja karyawan.

5) Untuk mengetahui apakah terdapat pengaruh antara Komitmen organisasi terhadap Kinerja karyawan.

6) Untuk mengetahui apakah pengaruh yang signifikan antara Kesehatan dan keselamatan kerja terhadap Kinerja karyawan dimediasi oleh Keterasingan kerja.

7) Untuk mengetahui apakah terdapat pengaruh yang signifikan antara Kesehatan dan keselamatan kerja terhadap Kinerja karyawan dimediasi oleh Komitmen organisasi.

\section{LANDASAN TEORI \\ Kinerja Karyawan}

Mangkunegara (2013), definisi Kinerja adalah pencapaian yang dimiliki seorang pekerja dalam menyelesaikan pekerjaannya baik dilihat berdasarkan kualitas maupun kuantitasnya sesuai dengan tanggungjawab yang telah diberikan. Sedangkan menurut Ahmad et al., (2017) Kinerja adalah output atas apa yang telah dikerjakan maupun tidak dikerjakan yang diterima oleh perorangan ataupun sekelompok orang didalam suatu organisasi. Sehingga dapat disimpulkan bahwa kinerja adalah output atas pencapaian kerja yang dimiliki pekerja baik dilihat berdasarkan secara kualitas maupun kuantitasnya sesuai dengan tanggung jawab yang diberikan.

Dalam meningkatkan kinerja pekerja ada beberapa faktor penentu, salah satunya adalah melakukan penerapan prosedur keselamatan dan kesehatan kerja, dimana perusahaan dapat memberikan fasilitas pelayanan kesehatan bagi tiap para pekerjanya secara rutin dan kontinu. Hal ini bertujuan agar kinerja pekerja tersebut dapat meningkat dikarenakan setiap pekerja mendapatkan jaminan atas pemeliharaan kesehatan tenaga kerja, dan juga lingkungan kerja yang aman dan sehat.

\section{Hubungan Antar Variabel}

\section{Keselamatan dan Kesehatan Kerja dengan Kinerja Karyawan}

Kartikasari (2017), menjelaskan bahwa dengan perusahaan memberikan atau menyediakan fasilitas keamanan kesehatan dan keselamatan kerja kepada karyawan untuk merasa aman di tempat kerja, dapat mengurangi risiko kecelakaan kecelakaan dan meningkatkan kenyamanan lingkungan kerja sehingga karyawan merasa terlindungi saat bekerja. Mengabaikan keselamatan di tempat kerja dapat menyebabkan banyak kerusakan dan cedera pada tenaga kerja yang tidak hanya akan menyebabkan kerugian finansial, tetapi juga pada hilangnya sumber daya manusia yang berharga, sehingga memengaruhi kinerja pekerjaan karyawan (Abu Nawwas et al., 2017a).

Penelitian ini konsisten dengan penelitian yang dilakukan oleh (Kaynak et al., 2016b), (Mwangi \& Waiganjo, 2017), (Abuga, 2012), (Hatani et al., 2018), (Putri et al., 2017), (Nderi \& Kirai, 2017), (Bayram et al., 2017), (Yusuf et al., 2012).

\section{Kesehatan dan Keselamatan Kerja dengan Keterasingan Kerja}

Keterasingan kerja adalah situasi yang menyebabkan baik negatif institusional maupun pribadi. Keterasingan menurunkan motivasi karyawan dan menyebabkan mereka menjauh dari pekerjaan secara psikologis dan mengurangi partisipasi dalam pekerjaan Pada akhirnya, keterasingan kerja muncul dengan cara kehilangan pekerjaan dan kepuasan hidup, produktivitas dan kinerja rendah, motivasi rendah, stres kerja yang tinggi, rendahnya kesetiaan pada pekerjaan dan organisasi, tingginya tingkat pergantian tenaga kerja dan pengintaian, ketidakpuasan terhadap bekerja, menjauh dari pekerjaan, dan persepsi kesehatan organisasi yang rendah. 

al., 2019).

Penelitian ini konsisten dengan penelitian yang dilakukan oleh (Kaynak et al., 2016b) dan (Özer et

\section{Kesehatan dan Keselamatan Kerja dengan Komitmen Organisasi}

Vinodkumar (2010), Praktik Safety and Health adalah strategi, kebijakan, kegiatan dan prosedur yang dapat diimplementasikan oleh organisasi yang menargetkan keselamatan karyawan mereka. Praktek keselamatan dan kesehatan kerja meliputi banyak komponen yang berhubungan dengan keselamatan seperti komitmen manajemen, pelatihan keselamatan, keterlibatan pekerja, aturan dan prosedur keselamatan dan kebijakan promosi keselamatan.

Penelitian ini selaras dengan penelitian yang dilakukan oleh (Kaynak et al., 2016b), (Al Zefeiti \& Mohamad, 2017), (Amponsah-tawiah \& Mensah, 2016) dan (Liu et al., 2019).

\section{Keterasingan kerja dengan Kinerja Karyawan}

Keterasingan kerja pertama kali diciptakan oleh Karl Marx yang memanfaatkan gagasan ini dengan tujuan akhir untuk meneliti dengan bebas tatanan sosial perusahaan. Gumpalan alienasi yang paling terkenal adalah empat faktor, yaitu ketidakberdayaan, tidak berarti, keterasingan sosial dan kebencian diri.. Para peneliti kebanyakan menekankan hubungan negatif antara alienasi dan output kinerja, seperti kinerja pekerjaan dan perilaku warga negara. Sebaliknya, telah dilaporkan hubungan positif dalam hal teoritis dan empiris sehubungan dengan absensi dan masalah kesehatan (Chiaburu et al., 2014).

Penelitian ini selaras dengan penelitian yang dilakukan oleh (Kaynak et al., 2016b), (Qader, 2017) dan (Guo et al., 2016).

\section{Komitmen Organisasi terhadap dengan Karyawan}

Menurut Hellriegel dan Slocum (2011), komitmen organisasi merupakan ketahanan hubungan pekerja terhadap organisasinya. Dimana pekerja yang bertahan dengan organisasi untuk jangka waktu yang lama, mereka cenderung memiliki komitmen yang lebih jika dibandingkan dengan pekerja dengan jangka waktu singkat. Menurut Mathis dan Jackson (2012), "komitmen organisasi terdiri dari komitmen karyawan terhadap perusahaan dan komitmen perusahaan terhadap karyawan".

Penelitian ini konstan dengan penelitian yang dilakukan oleh (Kaynak et al., 2016b) dan (Al Zefeiti \& Mohamad, 2017).

\section{Model Penelitian}

Model penelitian yang digunakan merupakan adaptasi dari model penelitian (Kaynak et al., 2016). Adapun model penelitian dapat dilihat pada Gambar 1

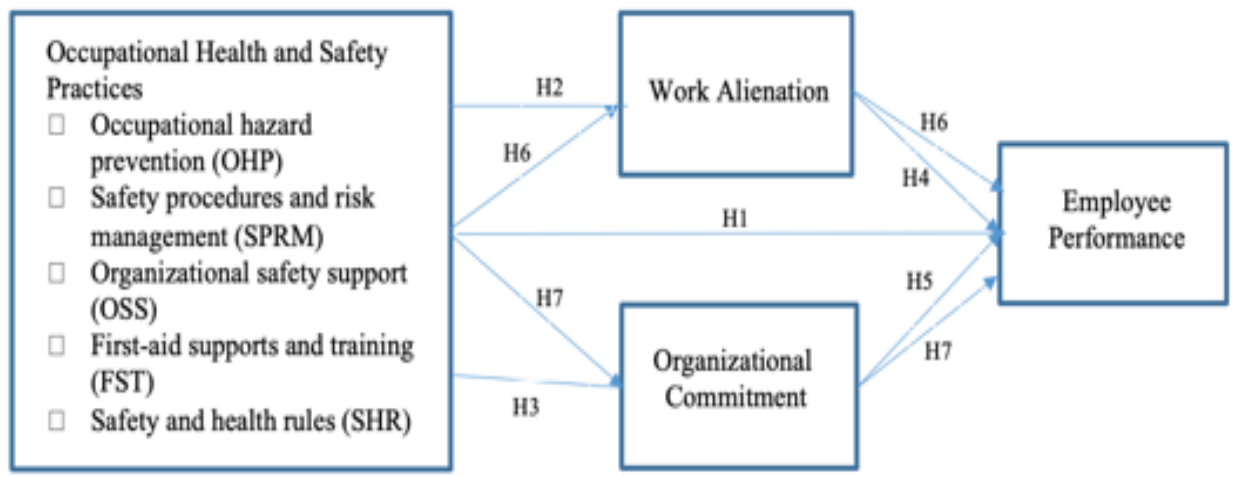

Gambar 1. Model penelitian

Berdasarkan kerangka model penelitian di atas, maka hipotesis untuk penelitian ini adalah:

H1: Kesehatan dan Keselamatan kerja berpengaruh signifikan terhadap Kinerja karyawan.

H2: Kesehatan dan Keselamatan kerja berpengaruh signifikan terhadap Keterasingan kerja.

H3: Kesehatan dan Keselamatan kerja berpengaruh signifikan terhadap Komitmen organisasi. 
H4: Keterasingan kerja mempunyai pengaruh signifikan terhadap Kinerja karyawan.

H5: Komitmen organisasi mempunyai pengaruh signifikan terhadap Kinerja karyawan.

H6: Kesehatan dan keselamatan kerja memiliki pengaruh signifikan terhadap Kinerja karyawan dimediasi oleh Keterasingan kerja.

H7: Kesehatan dan keselamatan kerja memiliki pengaruh signifikan terhadap Kinerja karyawan dimediasi oleh Komitmen organisasi.

\section{METODE PENELITIAN Rancangan Penelitian}

Jika dilihat berdasarkan jenis dan analisisnya penelitian ini termasuk kedalam jenis penelitian kuantitatif, yaitu menurut Robert Donmoyer (dalam Given, 2008) adalah pendekatan-pendekatan terhadap kajian empiris untuk mengumpulkan, menganalisa, dan menampilkan data dalam bentuk numeric dari pada naratif. Kemudian jika ditinjau penelitian berdasarkan sifat permasalahannya penelitian yang digunakan adalah desain deskriptif, yakni dimana dianggap sebagai strategi yang tepat dalam melakukan penelitian dikarenakan memungkinkan untuk dapat memperoleh informasi yang lebih banyak dari daerah yang diteliti, kemudian deskriptif secara tidak langsung sebagai penguji teori atau model dari beberapa perilaku atau situasi yang tidak dapat dipelajari dengan cara lain, serta, membantu dalam memahami karakteristik sekelompok populasi dalam situasi tertentu. Data yang akan digunakan dalam penelitian ini adalah data primer, dengan cara membagikan kuisioner kepada responden yang telah memenuhi kriteria penelitian. (Sugiyono, 2011).

Tujuan utama dari penelitian ini adalah untuk menganalisis pengaruh yang diberikan oleh Kesehatan dan Keselamatan Kerja sebagai variabel independen terhadap Kinerja Karyawan sebagai variabel dependen yang dimediasi oleh Keterasingan Kerja dan Komitmen Organisasi sebagai variabel mediasi.

\section{Objek Penelitian}

Populasi dalam penelitian ini adalah karyawan perusahaan yang bergerak dalam industri besar dimana memiliki banyak karyawan yang bekerja di departemen produksi ataupun bagian lapangan dan mengoperasikan mesin-mesin berat berteknologi tinggi, yang secara otomatis memerlukan penerapan sistem manajemen Kesehatan dan Keselamatan Kerja yang terpadu, sehingga memudahkan peneliti untuk melakukan penelitian dan mengumpulkan data-data yang berkaitan dengan judul penelitian.

Metode pengambilan sampel menggunakan metode Purposive Sampling, yaitu metode dimana peneliti menentukan pengambilan sampel dengan cara menetapkan kriteria yang sesuai dengan tujuan penelitian sehingga diharapkan dapat menjawab permasalahan penelitian. Adapun kriteria tersebut adalah sebagai berikut: Karyawan bagian produksi atau lapangan, perusahaan bergerak dalam industri besar, perusahaan yang memiliki tingkat resiko atau pun bahaya yang cukup tinggi, perusahaan yang proses pengoperasiannya menggunakan mesin-mesin berat berteknologi tinggi.

Berdasarkan data Badan Pengusahaan Batam mencatat ada 537 perusahaan asing yang beroperasi di Kota Batam. Industri - industri ini terdiri dari sektor Industri Manufaktur, Industri Galangan Kapal, Industri Fabrikasi dan beberapa Industri berat lainnya seperti Industri Pipa juga industri pendukung untuk Minyak dan Gas.

Adapun daftar perusahaan yang akan diteliti adalah sebagai berikut:

\begin{tabular}{lll}
\hline No & Nama Perusahaan & Bidang Industri \\
\hline 1 & PT. Nov-Profab & Industri Fabrikasi \\
2 & PT. Cladtek Bi-Metal Manufacturing & Industri Fabrikasi \\
\hline
\end{tabular}

Gambar 2. Daftar Perusahaan 
Kedua perusahaan industri fabrikasi pipa dan logam dengan orientasi pasar skala Internasional tersebut memiliki lokasi strategis, yakni terletak sekitar $15 \mathrm{~km}$ berhadapan langsung dengan wilayah laut Singapura dan Malaysia. Selain itu memiliki akses dekat dengan Pelabuhan Internasional Batu Ampar sehingga dapat memudahkan kapal dalam proses pengiriman dan penerimaan produk dimana hasil produk tersebut dipasarkan dibeberapa Negara besar seperti, Amerika, Australia, Indonesia, Singapura dan Brazil.

Dalam penelitian multivariative penentuan jumlah minimal sampel dihitung berdasarkan rumus sebagai berikut (Ferdinand, 2014):

$\mathrm{N} \quad=$ (jumlah indikator pertanyaan $\times 5)$

$=(45$ indikator pertanyaan $\times 5)$

$=225$ sampel

Jadi, jumlah sampel minimum dalam penelitian ini adalah 225 sampel.

Akan tetapi dalam penelitian ini peneliti menggunakan 300 sampel, guna menghindari terjadinya data tidak lengkap, ataupun kuesioner hilang dan tidak kembali.

\section{Definisi Operasional Variabel Kinerja Karyawan}

Performance atau kinerja dapat diartikan sebagai hasil akhir dari aktivitas seseorang atau organisasi. Variabel ini di uji dengan 5 pertanyaan.

\begin{tabular}{ll} 
No & \multicolumn{1}{c}{ Pernyataan } \\
\hline $1 \quad \begin{array}{l}\text { Saya selalu menyelesaikan tugas yang diberikan sesuai dengan } \\
\text { deskripsi pekerjaan yang saya miliki di tempat kerja. }\end{array}$ \\
$2 \quad \begin{array}{l}\text { Saya memenuhi tanggung jawab saya sebagaimana yang diminta di } \\
\text { dalam pekerjaan saya. }\end{array}$ \\
3 Saya tidak berhasil memenuhi tugas-tugas saya. \\
$\begin{array}{l}\text { Saya tidak mengabaikan tugas sebagaimana yang diminta di dalam } \\
\text { pekerjaan saya. }\end{array}$ \\
$\begin{array}{l}\text { Saya memenuhi tugas formal sesuai dengan yang diminta di dalam } \\
\text { pekerjaan saya. }\end{array}$
\end{tabular}

\section{Gambar 3. Instrumen Kinerja}

Instrumen penelitian di dapatkan dari artikel (Kaynak et al., 2016) yang diadaptasi dari artikel Goris et al., (2003). kemudian masing-masing pertanyaan diukur dengan menggunakan 5 poin skala likert.

\section{Kesehatan dan Keselamatan Kerja}

Menurut Wirawan (2015) kesehatan dan keselamatan kerja adalah segala kegiatan untuk menjamin dan melindungi keselamatan dan Kesehatan tenaga kerja melalui upaya pencegahan kecelakaan kerja dan penyakit akibat kerja. Variabel kesehatan dan keselamatan kerja akan diuji dengan 29 pertanyaan yang terbagi menjadi 5 bagian. 


No Pernyataan

1 Perusahaan saya menginformasikan setiap perubahan yang terjadi dalam pembagian kerja berdasarkan keahlian atau keterampilan khusus kepada pekerja.

2 Perusahaan saya telah mendefinisikan kemungkinan resiko-resiko dan hasil yang mungkin terjadi.

3 Perusahaan saya melakukan penyesuaian prosedur kerja secara tertulis berdasarkan praktik kerja yang ada.

4 Perusahaan saya memiliki prosedur yang memudahkan para pekerja untuk mengetahui setiap tugas yang diberikan.

5 Perusahaan saya memiliki beberapa pekerja kompeten untuk dapat melakukan pekerjaan tertentu yang dibutuhkan organisasi.

6 Perusahaan saya memiliki beban kerja yang cukup seimbang.

Gambar 4. Instrumen Kesehatan dan Keselamatan Kerja

No Pernyataan

1 Perusahaan saya memberikan pengaturan waktu istirahat yang cukup sesuai dengan pekerjaan yang berlangsung.

2 Perusahaan saya selalu menerapkan aturan keselamatan.

3 Perusahaan saya menjadikan aturan keselamatan sebagai program yang harus dipatuhi.

4 Perusahaan saya menerapkan aturan bagi calon pekerja untuk melakukan pemeriksaan kesehatan sebelum memulai bekerja untuk organisasi.

5 Perusahaan saya melakukan pemeriksaan kesehatan secara berkala bagi pekerja.

6 Perusahaan saya sebisa mungkin menghilangkan hal-hal yang dapat mengancam keselamatan dan kesehatan.

7 Perusahaan saya mempertimbangkan secara khusus kelompok (lanjut usia, cacat, dll) yang mendapatkan kebijakan khusus selama penilaian resiko.

Gambar 5. Instrumen Kesehatan dan Keselamatan Kerja 
1 Perusahaan saya menyediakan penanganan darurat apabila terjadi kecelakaan kerja.

2 Perusahaan saya memberikan pelatihan bagi pekerja dalam mengatasi bahaya kesehatan.

3 Perusahaan saya memberikan pelatihan kesehatan dan kebersihan bagi pekerja.

4 Perusahaan saya memberikan pelatihan pertolongan pertama bagi pekerja.

Gambar 6. Instrumen Kesehatan dan Keselamatan Kerja

\begin{tabular}{|c|c|}
\hline No & Pernyataan \\
\hline 1 & $\begin{array}{l}\text { Perusahaan saya mewajibkan penggunaan safety glasses, helmets, boots, } \\
\text { gloves, masks, jumpsuits dan shoes bagi pekerja dengan job desc(tugas } \\
\text { pekerjaan) yang memiliki tingkat resiko bahaya. }\end{array}$ \\
\hline 2 & $\begin{array}{l}\text { Akses keluar-masuk tempat khusus(memungkinkan memiliki tingkat } \\
\text { resiko bahaya) diberikan hanya kepada pekerja yang ditugaskan secara } \\
\text { khusus dengan peralatan yang diperlukan. }\end{array}$ \\
\hline 3 & $\begin{array}{l}\text { Pemantauan atau penghilangan atas kekurangan atau kesalahan di } \\
\text { ungkapkan selama audit internal untuk kesehatan dan keselamatan. }\end{array}$ \\
\hline 4 & $\begin{array}{l}\text { Terdapat pengaturan tata letak dan pencahayaan yang sesuai di pabrik } \\
\text { tempat saya bekerja. }\end{array}$ \\
\hline 5 & $\begin{array}{l}\text { Pembuangan limbah yang tepat dan efektif sedang berlangsung di pabrik } \\
\text { tempat saya bekerja. }\end{array}$ \\
\hline 6 & Terdapat perangkat kesehatan dan keselamatan di tempat saya bekerja. \\
\hline 7 & $\begin{array}{l}\text { Pekerja yang ditugaskan untuk tugas-tugas serius atau bahkan berbahaya } \\
\text { dilakukan pemantauan secara teratur melalui audit internal untuk dilihat } \\
\text { apakah mereka mengikuti instruksi dan prosedur yang diterapkan sesuai } \\
\text { dengan aturan kesehatan dan keselamatan kerja yang ada di organisasi } \\
\text { saya. }\end{array}$ \\
\hline
\end{tabular}

Gambar 7. Instrumen Kesehatan dan Keselamatan Kerja 


\begin{tabular}{ll}
\hline No & \multicolumn{1}{c}{ Pernyataan } \\
\hline 1 & $\begin{array}{l}\text { Tempat saya bekerja menyediakan perawatan medis yang cukup } \\
\text { memadai. }\end{array}$ \\
2 & Waktu yang cukup diberikan kepada pekerja agar dapat segera pulih. \\
3 & Kerusakan yang terjadi akan dibayarkan apabila terjadi cedera. \\
4 & Perusahaan saya mengikuti peraturan keselamatan kerja yang diterapkan. \\
5 & $\begin{array}{l}\text { Perusahaan saya melindungi privasi pekerja (catatan medis) tidak } \\
\text { diungkapkan. }\end{array}$ \\
\hline
\end{tabular}

Gambar 8. Instrumen Kesehatan dan Keselamatan Kerja

Instrumen penelitian didapatkan dari artikel (Kaynak et al., 2016) yang diadaptasi dari artikel Christopher et al., (2012), Glendon dan Litherland (2001) kemudian diukur dengan menggunakan 5 poin skala likert.

\section{Keterasingan Kerja}

Variabel keterasingan kerja diuji dengan 7 pertanyaan. Instrumen penelitian didapatkan dari artikel (Kaynak et al., 2016) yang diadaptasi dari artikel Nair dan Vohra (2010).

\begin{tabular}{ll}
\hline No & \multicolumn{1}{c}{ Pernyataan } \\
1 & $\begin{array}{l}\text { Saya merasa tidak senang dengan apa yang saya lakukan di } \\
\text { organisasi saya; Saya menghabiskan waktu hanya untuk dibayar. }\end{array}$ \\
2 & $\begin{array}{l}\text { Menghadapi tugas harian merupakan pengalaman yang menyakitkan } \\
\text { dan membosankan. }\end{array}$ \\
3 & Saya merasa diri saya terpisah atau jauh dari organisasi saya. \\
4 & Saya berharap saya dapat melakukan hal yang berbeda. \\
& $\begin{array}{l}\text { Belakangan ini, saya merasa kecewa dengan pekerjaan saya. } \\
6\end{array}$ \\
& $\begin{array}{l}\text { Saya merasa tidak menunjukkan upaya yang lebih baik dalam } \\
\text { pekerjaan saya. }\end{array}$
\end{tabular}

Gambar 9. Instrumen Keterasingan Kerja 


\section{Komitmen Organisasi}

Menurut Mathis dan Jackson (2012), "komitmen organisasi terdiri dari komitmen karyawan terhadap perusahaan dan komitmen perusahaan terhadap karyawan". Variabel Komitmen Organisasi diuji dengan 4 pertanyaan.

\begin{tabular}{ll}
\hline No & Pernyataan \\
\hline
\end{tabular}

1 Perusahaan ini secara pribadi sesuai dengan diri saya.

2 Saya merasa memiliki komitmen yang kuat untuk organisasi ini.

3 Saya merasa diri saya seperti anggota keluarga di dalam organisasi ini.

4 Saya merasa terlibat secara emosional dengan organisasi ini.

Gambar 10. Instrumen Komitmen Organisasi

Instrumen penelitian didapatkan dari artikel diadaptasi dari artikel Babin dan Boles (1998), Hartline dan Ferrell (1996 Netemeyer et al., (1997) kemudian masing-masing pertanyaan diukur dengan menggunakan 5 point skala likert.

\section{Teknik Pengumpulan Data}

Penelitian ini mendapatkan data primer untuk diolah melalui penyebaran kuesioner pengisian angket yang dilakukan secara langsung dibagikan kepada karyawan, data tersebut merupakan data yang didapatkan secara langsung dan berkaitan dengan objek penelitian. Data yang dibutuhkan dalam penelitian ini adalah persepsi karyawan perusahaan mengenai pengaruh kesehatan dan keselamatan kerja terhadap kinerja karyawan dengan keterasingan kerja dan komitmen organisasi sebagai variabel mediasi. Sedangkan data sekunder diperoleh melalui artikel, jurnal, internet dan buku.

\section{Metode Analisa Data}

Data primer yang telah berhasil dikumpulkan akan di-input dan diproses dengan menggunakan aplikasi SmartPLS 3.3 untuk mengetahui apakah terdapat pengaruh antara variabel independen terhadap variabel dependen yang dipengaruhi oleh variabel mediasi. Sedangkan untuk mengetahui data berdasarkan karakteristik responden peneliti akan menggunakan aplikasi SPSS.

Menurut Ningsi (2012), PLS terdiri dari hubungan eksternal (outer model atau model pengukuran) dan hubungan internal (inner model atau model struktural). Bersamaan dengan model struktural dan model pengukuran, model jalur dalam PLS terdiri dari tiga set hubungan : (1) inner model yang menspesifikasikan hubungan antar variabel laten, (2) outer model yang menspesifikasikan hubungan antara variabel laten dengan indikator atau manifesnya dan, (3) weight relation yang dapat menghitung skor variabel laten (Sanchez, 2013).

\section{Common Method Biases (CMB)}

Common Method Biases merupakan salah satu teknik yang paling sering digunakan oleh kebanyakan peneliti terdahulu untuk menunjukkan isu tentang CMB adalah Harman's one factor atau bisa disebut juga dengan Single Factor Test. Harman's single-factor test, prinsipnya adalah memasukkan semua butur dari semua konstruk penelitian dalam sebuah analisis faktor guna menentukan apakah mayoritas varian dapat dijelaskan oleh satu faktor umum. 
Dimana penelitian ini menyarankan agar tidak ada satupun single factor yang menjelaskan variance lebih dari 50\% agar mengindikasikan bahwa tidak terjadi $C M B$ dalam suatu penelitian.

\section{Evaluasi Model}

Model evaluasi PLS berdasarkan pada pengukuran prediksi yang mempunyai sifat no-parametrik. Oleh karena itu, model evaluasi PLS dilakukan dengan menilai outer model dan inner model.

\section{Outer Model ( Evaluasi Model Pengukuran )}

Evaluasi outer model disebut pula dengan evaluasi model pengukuran dilakukan untuk menilai validitas dan reliabilitas model.

\section{Uji Validitas}

Validitas, sering disebut validitas konstruk, mengacu pada sejauh mana suatu ukuran cukup mewakili konstruk yang seharusnya diukur. Pengujian validitas instrumen yang akan dilakukan adalah validitas konvergen yaitu kedekatan antara pengukuran dengan konstruk yang diukur (Bhattacherjee, 2012).

Uji validatas convergent indikator refleksif dapat dilihat dari nilai loading factor untuk setiap konstruk, dimana nilai loading factor yang direkomendasikan harus lebih besar dari 0,7 untuk penelitian yang bersifat confirmatory dan nilai loading factor antara 0,6 - 0,7 untuk penelitian yang bersifat exploratory masih dapat diterima, serta nilai average variance extracted (AVE) harus lebih besar dari 0,5.

\section{Uji Reliabilitas}

Uji reliabilitas suatu konstruk dengan indikator refleksif dapat dilakukan dengan dua cara yaitu Composite Reliability dan Cronbach's Alpha. Akan tetapi penggunaan Cronbach's Alpha untuk menguji reliabilitas konstruk akan memberikan nilai yang lebih rendah (under estimate) sehingga disarankan untuk menggunakan Composite Reliability untuk menguji reliabilitas suatu konstruk (Ghozali \& Latan, 2012).

Composite Reliability merupakan closer approximation dengan asumsi estimasi parameter adalah akurat (Chin 1998; 2010). Suatu konstruk dikatakan reliabel apabila nilai Composite Reliability lebih besar dari 0,70 (Chin, 1998 dan Hair et al., 2011).

\section{Inner Model (Evaluasi Model Struktural)}

Inner model dilakukan untuk memprediksi hubungan antar variabel laten, baik hubungan yang bersifat langsung (direct effect) maupun hubungan tidak langsung melalui variabel mediasi (Indirect effect).

\section{Indirect Effect}

Indirect effect menunjukkan besarnya pengaruh secara tidak langsung dari variabel laten terhadap variabel laten lainnya yang melalui variabel mediasi. Signifikansi dari hubungan tersebut dapat dilihat juga pada table Total Indirect Effects yaitu pada kolom T-Statistics (Ghozali dan Latan, 2012). Suatu hubungan dikatakan signifikan dengan tingkat signfikansi 5\% jika memiliki nilai $T$-statistics lebih dari 1,96 atau Pvalues $<0.05$ (Hair et al,. 2011).

\section{Path Coefficients}

Path coefficients menunjukkan besar pengaruh yang ditunjukkan oleh variabel laten terhadap variabel laten lainnya. Signifikansi dari hubungan tersebut dapat dilihat juga pada tabel path coefficients yaitu pada kolom T-Statistics (Ghozali dan Latan, 2012). Suatu hubungan dikatakan signifikan dengan tingkat signfikansi 5\% jika memiliki nilai $T$-statistics lebih dari 1,96 atau P-values $<0.05$ (Hair et al., 2011).

\section{R-Square}

Nilai R-Squares merupakan uji goodness fit model. Perubahan nilai R-Squares digunakan untuk menjelaskan pengaruh variabel laten eksogen tertentu terhadap variabel laten endogen, apakah mempunyai pengaruh substantive. Nilai $R$-Squares 0,$67 ; 0,33$ dan 0,19 untuk variabel laten endogen dalam model struktural menunjukkan model kuat, moderat, dan lemah (Chin, 1998 dalam Ghozali, 2012). 


\section{IV, HASIL DAN PEMBAHASAN}

Dirincikan pada Bab metode penelitian bahwa penggunaan minimal 225 dalam penelitian ini dengan mendistribusikan survei ke 2 (dua) perusahaan di bidang industri fabrikasi yang berada di wilayah Kawasan Batu Ampar. Dari 300 target kuesioner, terdapat 278 data responden yang dapat digunakan sebagai data penelitian.

Hasil distribusi demografi responden dapat lihat pada:

\begin{tabular}{|c|c|c|c|}
\hline \multicolumn{2}{|c|}{ Karakteristik } & Jumlah & Persentas \\
\hline \multirow{3}{*}{ Usia } & $18-25$ Tahun & 123 & 44.2 \\
\hline & $26-35$ Tahun & 149 & 53.6 \\
\hline & $36-45$ Tahun & 6 & 2.2 \\
\hline \multirow{2}{*}{ Jenis Kelamin } & Laki-Laki & 252 & 90.6 \\
\hline & Perempuan & 26 & 9.4 \\
\hline \multirow{4}{*}{ Pendidikan Terakhir } & SMA/SMK sederajat & 40 & 14.4 \\
\hline & D3 & 97 & 34.9 \\
\hline & $\mathrm{D} 4 / \mathrm{S} 1$ & 139 & 50 \\
\hline & S2 & 2 & 0.7 \\
\hline \multirow{2}{*}{ Status Pernikahan } & Belum Menikah & 102 & 36.7 \\
\hline & Menikah & 176 & 63.3 \\
\hline \multirow{2}{*}{ Perusahaan } & PT. NOV Profab & 138 & 49.6 \\
\hline & PT. Cladtek Bi-Metal Manufacturing & 140 & 50.4 \\
\hline \multirow{4}{*}{ Posisi Kerja } & Technical Employee & 114 & 41 \\
\hline & Engineer & 148 & 53.2 \\
\hline & Supervisor & 11 & 4 \\
\hline & Expert/Professional & 5 & 1.8 \\
\hline
\end{tabular}

Gambar 11. Distribusi Demografi Responden. Sumber: Data diolah (2021)

Jika mengamati Gambar 11 di atas, berdasarkan range usia dapat disimpulkan bahwa persentase responden terbesar adalah usia $26 \mathrm{~s} / \mathrm{d} 35$ tahun yaitu sebesar $53.6 \%$ atau sebanyak 149 responden, kemudian persentase responden lainnya adalah antara usia $18 \mathrm{~s} / \mathrm{d} 25$ tahun yakni sebesar $44.2 \%$ atau sebanyak 123 responden, dan sisa lainnya pada kelompok usia $36 \mathrm{~s} / \mathrm{d} 45$ tahun yakni $2.2 \%$ atau sebanyak 6 orang menjawab.

Seperti yang terlihat pada Gambar 11 di atas, persentase responden tertinggi adalah laki-laki yakni sebanyak 252 orang (90.6\%). Kemudian bagian lainnya datang dari 26 (9.4\%) responden perempuan yang menjawab.

Jika diamati Gambar 11 diatas, responden memiliki tingkat Pendidikan akhir tertinggi pada jenjang D4 atau S1 yaitu 50\% atau 139, kemudian yang kedua pada jenjang D3 yaitu 34.9\% atau 97 responden, dan sebagian kecil lainnya pada jenjang SMA atau SMK sederajat yaitu 40 responden(14.4\%) dan dari jenjang S2 yakni sebanyak 2 responden $(0.7 \%)$.

Jika mengamati Gambar 11 di atas, persentase responden tertinggi dalam status mereka berasal 63.3\% atau 176 orang menikah, dan sebagian lainnya $36.7 \%$ atau 102 orang belum menikah.

Seperti terlihat pada Gambar 11 di atas, jumlah responden terbanyak berasal dari PT. Cladtek BiMetal Manufacturing memiliki 140 responden atau sebesar 50.4\%, jumlah responden dari PT. NOV Profab diwakili 138 responden atau sebanyak $49.6 \%$.

Berdasarkan Gambar 11 di atas, responden dengan persentase terbanyak berasal dari responden dengan posisi kerja sebagai engineer yakni sebesar 53.2\% atau 148 responden, terbanyak kedua berasal dari responden dengan posisi kerja sebagai technical employee yaitu sebanyak 114 responden atau sebesar $41 \%$, kemudian Sebagian kecil lainnya berasal dari responden dengan posisi kerja supervisor sebanyak 11 responden atau 4\% dan responden dengan posisi kerja expert/professional sebanyak 5 responden atau $1.8 \%$. 


\section{Hasil Uji Common Method Biases (CMB)}

Metode bias umum ialah tes yang biasa digunakan oleh peneliti guna melihat hasil tes CMB. Artinya, itu adalah Harman's one factor atau Single Factor test menggunakan teknik ini dan tidak ada single factor yang menyumbang varian lebih besar dari 50\%, sehingga dapat disimpulkan bahwa tidak ada bias metodologis umum didalam penelitian.

\begin{tabular}{lcc}
\hline Total & \% of Variance & Cumulative\% \\
\hline 15.681 & 34.848 & 34.848 \\
\hline
\end{tabular}

Gambar 12. Hasil Uji Common Method Biases. Sumber: Data diolah, (2021)

\subsection{Outer Model (Evaluasi Model Pengukuran)}

Dari 45 pertanyaan yang diajukan tersisa 34 pertanyaan dinyatakan valid. Berdasarkan hasil uji validasi 34 pertanyaan dijumpai valid dikarenakan semua pertanyaan ini disebabkan oleh nilai rata-rata yang diektraksi dari varians (AVE) lebih besar dari 0,5. Adapun jumlah pertanyaan kuesioner yang diajukan dapat dilihat pada gambar 13:

\begin{tabular}{ccc}
\hline Variabel & Sebelum & Sesudah \\
\hline Safety Procedures and Risk Management & 6 & 3 \\
Safety and Health Rules & 7 & 6 \\
First-aid Support and Trainings & 4 & 4 \\
Occupational Hazards Prevention & 7 & 5 \\
Occupational Safety Supports & 5 & 4 \\
Work Alienation & 7 & 5 \\
Organizational Commitment & 4 & 3 \\
Employee Performance & 5 & 3 \\
\hline
\end{tabular}

Gambar 13. Jumlah Pertanyaan yang diajukan. Sumber: Data diolah, (2021)

\begin{tabular}{ccc}
\hline Variabel & $\begin{array}{c}\text { Average Variance Extracted } \\
(\boldsymbol{A V E})\end{array}$ & Kesimpulan \\
\hline $\begin{array}{c}\text { Occupational Safety and Health } \\
\text { Practices }\end{array}$ & 0.542 & Valid \\
Work Alienation & 0.637 & Valid \\
Organizational Commitment & 0.602 & Valid \\
Employee Performance & 0.557 & Valid \\
\hline
\end{tabular}

Gambar 14. Hasil Uji Validitas. Sumber: Data diolah, (2021) 
Seperti yang terlihat pada Gambar 14 di atas, hasil uji validitas untuk semua item yang dinyatakan valid dengan nilai pertanyaan yang diajukan lebih besar dari 0,5. Occupational Safety and Health Practices, Work Alienation, Organizational Commitment dan Employee Performance. Ketika dilakukan uji validasi, nilai AVE lebih besar dari 0,5. Berdasarkan hasil tersebut dapat disimpulkan bahwa keempat variable tersebut telah valid dan memenuhi syarat validitas konvergen (Ghozali, 2011).

\begin{tabular}{ccc}
\hline Variabel & Composite Reliability & Kesimpulan \\
\hline $\begin{array}{c}\text { Occupational Safety and Health } \\
\text { Practices } \\
\text { Work Alienation }\end{array}$ & 0.962 & Reliable \\
Organizational Commitment & 0.896 & Reliable \\
Employee Performance & 0.822 & Reliable \\
\hline
\end{tabular}

Gambar 15. Hasil Uji Reliabilitas. Sumber: Data diolah, (2021)

Jika diamati Gambar 15 di atas, Adapun nilai composite reliability dari occupational safety and health practices 0,962 , work alienation 0,896 , orgazational commitment 0,822 dan employee performance 0,788 . Hal tersebut menunjukkan bahwa keseluruhan variable memiliki nilai composite reliability lebih dari 0,70 yang berarti reliabel (Imam, 2012).

\section{Inner Model (Evaluasi Model Struktural)}

\begin{tabular}{|c|c|c|c|c|}
\hline \multicolumn{2}{|r|}{ Jalur } & \multicolumn{3}{|c|}{ Values Statistics KesImpulan } \\
\hline Occupatio & $\begin{array}{l}\text { onal Safety and Health Practices } \rightarrow \\
\text { Employee Performance }\end{array}$ & 0.000 & 4.781 & H1: Diterima \\
\hline Occupational & $\begin{array}{l}\text { Safety and Health Practices } \rightarrow \text { Work } \\
\text { Alienation }\end{array}$ & 0.001 & 20.969 & H2: Diterima \\
\hline Occupati & $\begin{array}{l}\text { tional Safety and Health Practices } \rightarrow \\
\text { Organizational Commitment }\end{array}$ & 0.000 & 3.481 & H3: Diterima \\
\hline Work Al & lienation $\rightarrow$ Employee Performance & 0.063 & 1.863 & H4: Ditolak \\
\hline Organizationa & al Commitment $\rightarrow$ Employee Performance & 0.000 & 7.639 & H5: Diterima \\
\hline $\mathrm{X}$ & $\mathrm{Z}$ & & & \\
\hline $\begin{array}{l}\text { Occupational } \\
\text { Safety and } \\
\text { Health } \\
\text { Practices }\end{array}$ & $\begin{array}{c}\text { Employee } \\
\text { Performance }\end{array}$ & 0.064 & 1.854 & H6: Ditolak \\
\hline $\begin{array}{l}\text { Occupational } \\
\text { Safety and } \\
\text { Health } \\
\text { Practices } \\
\end{array}$ & Organizational Commitment $\begin{array}{c}\text { Employee } \\
\text { Performance }\end{array}$ & 0.000 & 3.616 & H7: Diterima \\
\hline
\end{tabular}

Note: signifikan apabila nilai p-values $<0,05$, atau nilai t-statistics $>1,96$

Gambar 16. Hasil Uji Model Struktural. Sumber: Data diolah, (2021) 


\section{JESYA}

JURNAL EKONOMI \& EKONOMI SYARIAH

Jurnal Ekonomi \& Ekonomi Syariah Vol 5 No 1, Januari 2022

E-ISSN : 2599-3410 | P-ISSN : 2614-3259

DOI : https://doi.org/10.36778/jesya.v5i1.558

\section{Hipotesis 1}

Gambar 16 di atas, menunjukkan nilai t-statistics yaitu 4,781. Diartikan bahwa occupational safety and health practices berpengaruh signifikan terhadap employee performance. Hal ini selaras dengan yang ditemukan oleh peneliti sebelumnya (Kaynak et al., 2016b), (Mwangi \& Waiganjo, 2017), (Abuga, 2012), (Hatani et al., 2018), (Putri et al., 2017), (Nderi \& Kirai, 2017), (Bayram et al., 2017), (Yusuf et al., 2012). Sehingga dapat disimpulkan bahwa occupational safety and health practices memberikan pengaruh terhadap peningkatan kinerja karyawan perusahaan yang disebabkan beberapa faktor dimana perusahaan telah berhasil dalam menjamin dan memelihara kesehatan semua pekerja di tempat kerja, dan memastikan semua sumber daya produksi dipelihara dengan baik dan digunakan dengan cara yang aman dan efisien. Sebagaimana Kartikasari (2017), menjelaskan bahwa dengan perusahaaan memberikan atau menyediakan fasilitas keamanan, kesehatan dan keselamatan kerja kepada karyawan untuk merasa aman di tempat kerja, dapat mengurangi risiko kecelakaan-kecelakaan dan meningkatkan kenyamanan lingkungan kerja sehingga karyawan merasa terlindungi saat bekerja. Mengabaikan keselamatan di tempat kerja dapat menyebabkan banyak kerusakan dan cedera pada tenaga kerja yang tidak hanya akan menyebabkan kerugian finansial, tetapi juga hilangnya sumber daya manusia yang berharga, sehingga memngaruhi kinerja pekerjaan karyawan (Abu Nawwas et al., 2017b).

\section{Hipotesis 2}

Gambar 16 di atas, menunjukkan nilai t-statistics yaitu 20,969. Diartikan bahwa occupational safety and health practices berpengaruh signifikan terhadap work alienation. Hal ini selaras dengan yang ditemukan oleh peneliti sebelumnya (Kaynak et al., 2016b) dan (Özer et al., 2019). Sehingga dapat disimpulkan bahwa occupational safety and health practices memberikan pengaruh positif bagi karyawan perusahaan dimana menandakan perusahaan telah berhasil dalam penerapan sistem manajemen $\mathrm{k} 3$ yang dimilikinya sehingga tidak terjadinya keterasingan kerja di lingkungan perusahaan tersebut. Adapun beberapa faktor yang mempengaruhi hal tersebut seperti, persepsi kesehatan organisasi yang tinggi, stress kerja yang rendah, motivasi yang tinggi serta kepuasaan karyawan terhadap pekerjaannya.

\section{Hipotesis 3}

Gambar 16 di atas, menunjukkan nilai t-statistics yaitu 3,481. Diartikan bahwa occupational safety and health practices berpengaruh signifikan terhadap organizational commitment. Hal ini selaras dengan yang ditemukan oleh peneliti sebelumnya (Kaynak et al., 2016b), (Al Zefeiti \& Mohamad, 2017), (Amponsah-tawiah \& Mensah, 2016) dan (Liu et al., 2019). Sehingga dapat disimpulkan bahwa occupational safety and health practices memberikan pengaruh bagi komitmen organisasi sebagaimana menurut Vinodkumar (2010), praktik safety and health adalah strategi, kebijakann, kegiatan dan prosedur yang dapat diimplementasikan oleh organisasi yang menargetkan keselamatan karyawan mereka. Praktek keselamatan dan Kesehatan kerja meliputi banyak komponen yang berhubungan dengan keselamatan, keterlibatan pekerja, aturan dan prosedur keselamatan dan kebijakan promosi keselamatan.

\section{Hipotesis 4}

Gambar 16 di atas, menunjukkan nilai t-statistics yaitu 1,863. Diartikan bahwa work alienation berpengaruh tidak signifikan terhadap employee performance. Hal ini tidak selaras dengan yang ditemukan oleh peneliti sebelumnya (Kaynak et al., 2016b), (Qader, 2017) dan (Guo et al., 2016). Hal ini menunjukkan bahwa work alienation tidak ada pengaruh ataupun efek negative yang dapat menurunkan tingkat performance kerja yang dimiliki oleh pekerja yang berada pada perusahaan PT. NOV Profab dan PT. Cladtek Bi-Metal Manufacturing, dimana para pekerja tersebut tidak merasakan adanya keterasingan kerja dilingkungan kerjanya.

\section{Hipotesis 5}

Gambar 16 di atas, menunjukkan nilai t-statistics yaitu 7,639. Diartikan bahwa organizational commitment berpengaruh signifikan terhadap employee performance. Hal ini selaras dengan yang ditemukan oleh peneliti sebelumnya (Kaynak et al., 2016b) dan (Al Zefeiti \& Mohamad, 2017). Sehingga dapat disimpulkan bahwa komitmen organisasi memiliki pengaruh bagi peningkatan kinerja karyawan sebagaimana menurut Hellriegel dan Scolum (2011), komitmen organisasi merupakan ketahanan hubungan pekerja terhadap organisasinya. Dimana pekerja yang bertahan dengan organisasi untuk jangka waktu yang 
lama, mereka cenderung memiliki komitmen yang lebih jika dibandingkan dengan pekerja dengan jangka waktu singkat.

\section{Hipotesis 6}

Gambar 16 di atas, menunjukkan nilai t-statistics yaitu 1,854. Diartikan bahwa occupational safety and health practices berpengaruh tidak signifikan terhadap employee performance yang dimediasi oleh work alienation. Hal ini tidak konsisten seperti yang ditemukan oleh peneliti terdahulu (Kaynak et al., 2016b). Hal ini menunjukkan bahwa work alienation tidak mampu memediasi pengaruh yang dimiliki oleh occupational safety and health practices terhadap kinerja karyawan, itu berarti bahwa praktik kesehatan dan keselamatan kerja yang dimiliki oleh perusahaan sudah cukup berhasil dalam penerapannya sehingga hal tersebut dapat mengurangi tingkat keterasingan kerja yang memungkinkan terjadi didalam organisasi, dimana hal tersebut dapat memberikan pengaruh bagi penurunan tingkat kinerja yang dimiliki oleh karyawan. Sebagaimana menurut Ozer (2019), Kesehatan suatu organisasi dapat mempengaruhi baik sistem kerja organisasi, desain dan prosedur manajemen, dan juga pengaruh organisasi terhadap perilaku karyawan dan tingkat stress serta kesehatan karyawan. Selain itu juga dapat memberikan efek positif dengan meningkatkan kinerja dan hubungan kerja karyawan yang mana adanya komunikasi yang efektif antara rekan kerja dan manajer dalam organisasi yang sehat.

\section{Hipotesis 7}

Gambar 16 di atas, menunjukkan nilai t-statistics yaitu 3,616. Diartikan bahwa occupational safety and health practices berpengaruh signifikan terhadap employee performance yang dimediasi oleh organizational commitment. Hal ini selaras dengan yang ditemukan oleh peneliti sebelumnya (Kaynak et al., 2016b). sehingga dapat disimpulkan bahwa occupational safety and health practices memiliki pengaruh terhadap peningkatan kinerja karyawan yang dimediasi oleh komitmen organisasi sebagaimana menurut Amponsah dan Mensah (2016), persepsi karyawan mengenai manajemen kesehatan dan keselamatan kerja dalam organisasi mempengaruhi keputusan mereka untuk tetap tinggal di organisasi dan memberikan kontribusi yang bermanfaat bagi organisasi. Dimana ketika karyawan merasa bahwa manajemen kesehatan dan keselamatan kerja dalam organisasi sudah tepat dan memadai, kemungkinan besar mereka yang memiliki hubungan berkelanjutan dengan organisasi mengetahui bahwa kesehatan dan keselamatan kerja mereka telah terjamin dalam organisasi.

\section{Hasil Uji Adjusted R2 square}

\begin{tabular}{lccc}
\hline & Jalur & Adjusted & \\
& $\mathrm{x} \rightarrow \mathrm{y}$ & Keterangan \\
$R^{2}$ square & \\
\hline Work Alienation & 0.382 & Moderat \\
Organizational Commitment & 0.043 & Lemah \\
Employee Performance & 0.466 & Moderat \\
\hline
\end{tabular}

Gambar 17. Hasil Uji Adjusted R2 Square. Sumber: Data diolah, (2021)

Mengacu pada hasil Gambar 17 di atas, penulis menarik tiga kesimpulan.

Pertama, penulis menyimpulkan bahwa nilai Adjusted $R^{2}$ square occupational satefy and health practice terhadap work alienation yaitu $38,2 \%$ hasil ini memaparkan bahwa variable independent ketika menginterpretasikan variable mediasi. Dengan demikian disimpulkan bahwa sebanyak 38,2\% variable occupational satefy and health practice mampu menjelaskan variable mediasi work alienation dan sisanya 61,8\% dipaparkan oleh faktor lain yang tidak termasuk dalam model (Ghozali, 2012).

Kedua, nilai Adjusted $R^{2}$ square occupational satefy and health practice terhadap organizational commitment adalah 4,3\% disimpulkan bahwa variable independent ketika menginterpretasikan variable mediasi. Dengan demikian disimpulkan bahwa variable occupational satefy and health practice hanya 
mampu menjelaskan variable mediasi organizational commitment sebanyak 4,3\% dan sisanya $95,7 \%$ dipaparkan oleh faktor lain yang tidak termasuk dalam model (Ghozali, 2012).

Terakhir, Adjusted $R^{2}$ square occupational satefy and health practice terhadap employee performance yaitu $46,6 \%$ disimpulkan bahwa variable independent ketika menginterpretasikan variable dependen. Sehingga dapat disimpulkan bahwa sebanyak 46,6\% variable occupational satefy and health practice mampu menjelaskan variable dependen employee performance dan sisanya 53,4\% dipaparkan oleh faktor lain yang tidak termasuk dalam model (Ghozali, 2012).

\section{KESIMPULAN}

Hasil penelitian didasarkan pada survei 278 responden yang dibuat dengan 7 hipotesis yang diajukan. 5 hipotesis tditerima dan 2 lainnya ditolak, berikut adalah hipotesis:

Occupational safety and health memiliki t-statistic sebilangan 4,781 yang berpengaruh signifikan terhadap employee performance jadi (H1) diterima. Occupational safety and health memengaruhi secara signifikan terhadap work alienation dengan nilai t-statistic sebilangan 20,969 maka (H2) diterima. Occupational safety and health memiliki pengaruh signifikan terhadap organizational commitment dengan nilai t-statistic sebilangan 3,481 maka (H3) diterima.

Selanjutnya, work alienation berpengaruh tidak signifikan terhadap employee performance dengan t-statistics sebilangan 1,863 jadi (H4) ditolak. Organizational commitment mempunyai pengaruh signifikan terhadap employee performance dengan nilai t-statistic sebilangan 7,639 maka (H5) diterima. Occupational safety and health mempunyai pengaruh tidak signifikan terhadap employee performance yang dimediasi oleh work alienation dengan nilai t-statistic sebilangan 1,854 maka (H6) ditolak. Occupational safety and health memengaruhi secara signifikan terhadap employee performance yang dimediasi oleh organizational commitment dengan nilai t-statistic sebilangan 1,854 atau lebih dari 1,96, maka (H7) diterima.

\section{Keterbatasan}

Batasan yang dimiliki dalam penelitian tesis ini adalah sebagai berikut:

1) Penelitian ini hanya dilakukan pada 2 Perusahaan yang bergerak dibidang Industri Fabrikasi di Kota Batam, sehingga tidak sepenuhnya mewakili seluruh Industri Fabrikasi yang ada di Kota Batam.

2) Penelitian ini dilakukan ditengah terjadinya pandemi covid-19 sehingga terdapat beberapa hambatan dalam proses pengumpulan data memakan waktu lebih lama dimana peneliti menggunakan kuesioner online dalam penyebarannya dikarenakan adanya aturan pembatasan aktivitas masyarakat yang diberlakukan oleh Pemerintah Kota.

3) Data yang sulit didapat, dikarenakan lemahnya tingkat partisipasi responden dalam pengisian kuesioner dalam masa pandemi covid-19 yang terjadi.

4) Variable penelitian ini hanya mencakup lingkup occupational safety and health (safety procedures and risk management, safety health rules, first-aid support and trainings, occupational hazards prevention, organizational safety support), work alienation, organizational commitment dan employee performance.

\section{Rekomendasi}

Beberapa rekomendasi bahkan dapat digunakan oleh peneliti dan perusahaan:

1) Pilih objek penelitian sesuai, dimana objek dapat mewakili studi yang dimaksud.

2) Perluas cakupan penyebaran penelitian untuk memaksimalkan sampel yang didapatkan untuk penelitian.

3) Pekerja sebagai sumber daya manusia memiliki peran penting bagi berjalannya aktivitas-aktivitas perusahaan, sehingga penting untuk dapat mempertahankan tingkat loyalitas dan juga kinerja yang dimilikinya.

4) Peningkatan mutu dan produktivitas kinerja pekerja juga dipengaruhi oleh kondisi lingkungan kerja yang sehat dan aman, maka untuk tetap mempertahankan hal tersebut perusahaan harus secara konsisten mempertahankan komitmen dan kebijakannya terhadap penerapan sistem manajemen k3 yang dimilikinya dengan melakukan pengawasan secara berkelanjutan, agar efektifitas penerapan k3 dapat mengurangi tingkat risiko terjadinya kecelakaan maupun penyakit akibat kerja.

5) Perusahaan haruslah memiliki sikap kesiapsiagaan darurat untuk diterapkan dalam sistem manajemen k3 nya guna menghadapi situasi krisis seperti pandemic covid-19 ini, agar dapat 
mencegah dan mengurangi tingkat risiko psikososial dimana para pekerja mengalami peningkatan risiko stress akibat wabah.

\section{Implikasi Manajerial}

Berdasarkan temuan dalam penelitian ini adalah terdapat pengaruh signifikan antara occupational safety and health practices terhadap kinerja karyawan, occupational safety and health practices terhadap keterasingan kerja, occupational safety and health practices terhadap komitmen organisasi, komitmen organisasi terhadap kinerja karyawan dan occupational safety and health practices terhadap kinerja karyawan dimediasi oleh komitmen organisasi. Implikasi manajerial dari temuan ini dapat dilakukan sebagai berikut:

Sebagaimana dalam UU No. 1 Tahun 1970 dijelaskan bahwa tujuan Keselamatan dan Kesehatan kerja yakni melakukan aktivitas kerja secara aman dan efisien mengikuti anjuran prosedur keamanan dan keselamatan serta menggunakan alat perlindungan diri sehingga dapat terhindar dari kemungkinan terjadinya kecelakaan ataupun sakit akibat kerja. Adapun fungsi dan tujuan k3 yang perlu diterapkan oleh perusahaan adalah sebagai berikut: menjamin dan memelihara Kesehatan dan keselamatan pekerja di tempat kerja guna terciptanya lingkungan kerja yang aman dan efisien sehingga dapat meningkatkan efisiensi kerja. Selain itu menurut Ozer et al., (2019), organisasi yang sehat ditentukan oleh tiga faktor yakni karyawan, organisasi dan kondisi kerja.

Perusahaan menyediakan fasilitas alat perlindungan diri (APD) dan juga Pemberian sosialisasi akan pentingnya penerapan $\mathrm{k} 3$ perusahaan bagi karyawannya. Dengan begitu dapat menyadarkan karyawan untuk selalu mengikuti aturan maupun prosedur k3 yang telah diterapkan oleh organisasi dengan memakai atribut lengkap dari alat pelindung diri (APD) yang telah disediakan tadi oleh organisasi guna menjaga Kesehatan dan keselamatan kerjanya. Selain itu juga perusahaan melakukan pengontrolan ataupun pengawasan bagi karyawan dengan begitu dapat memberikan dukungan ataupun perhatian pimpinan terhadap karyawannya sehingga dapat meningkatkan semangat maupun kinerja karyawan itu sendiri.

\section{DAFTAR PUSTAKA}

Abu Nawwas, O. M., Ariff, T. M., Alglilat, M. M., \& Latif, A. Z. A. (2017b). Could Occupational Safety and Health Systems Improve Employees' Performance in Arab Nations? The International Journal of Social Sciences and Humanities Invention, 4(7). https://doi.org/10.18535/ijsshi/v4i8.15

Abuga, G. (2012). Effect of Occupational Safety and Health Programs on Employee Performance (A case of Pyrethrum Board of Kenya).

Ahmad, I., Sattar, A., \& Nawaz, A. (2017). The Mediating Role of Perceived Job Satisfaction in the Relationship Between Occupational Health \& Safety and Employees' Performance. Gomal Journal of Medical Sciences, 15(1), 52-56.

Al Zefeiti, S. M. B., \& Mohamad, N. A. (2017). The Influence of Organizational Commitment on Omani Public Employees' Work Performance. International Review of Management and Marketing, 7(2), 151-160. http:www.econjournals.com

Amponsah-tawiah, K., \& Mensah, J. (2016). Occupational Health and Safety and Organizational Commitment : Evidence from the Ghanaian Mining Industry. Safety and Health at Work, 7(3), 225230. https://doi.org/10.1016/j.shaw.2016.01.002

Awan, K. Z., Qureshi, I.-W., Akram, M., \& Shahzad, K. (2014). Mediation Role of Organizational Commitment in the Relationships of Organizational Politics and Job Involvement and Employee Performance. 3(6), 1-20. https://doi.org/10.6007/IJAREMS/v3-i6/1267

Bayram, M., Ünğan, M. C., \& Ardıç, K. (2017). The Relationships between OHS Prevention Costs, Safety Performance, Employee Satisfaction and Accident Costs. International Journal of Occupational Safety and Ergonomics, 23(2), 285-296. https://doi.org/10.1080/10803548.2016.1226607

Boon, L. K., Fern, Y. S., Sze, C. C., \& Stanley. (2012). Factors Affecting Individual Job Performance. International Conference on Management, Economics and Finance (ICMEF 2012) Proceeding, October.

Dwomoh, G., Owusu, E. E., \& Addo, M. (2013). Impact of Occupational Health and Safety Policies on Employees' Performance in the Ghana's Timber Industry: Evidence from Lumber and Logs Limited. International Journal of Ed, 1(12), 1-14.

Gamal, N. L., Taneo, S. Y. M., \& Halim, L. (2018). Job Satisfaction As a Mediation Variable in the Relationship Between Work Safety and Health (K3) and Work Environment To Employee Performance. Jurnal Aplikasi Manajemen, 16(3), 486-493. 
https://doi.org/10.21776/ub.jam.2018.016.03.13

Guo, W., Dai, R., \& Yang, J. (2016). The Effect of Leadership Task Behavior and Relational Behavior on Job Performance: Investigating the Moderating Role of Work Alienation. April, 97-110.

Hatani, L., Amirullah, M., Nurwati, Adam, L. O. B., Aidin, Kalimin, L. O., Asfahyadin, L. O., \& Husin. (2018). Occupational Health and Safety (OHS) Towards Employee Performance: The Mediating Role of Work Motivation. International Business Management, 12(1), 103-116.

Kaynak, R., Tuygun Toklu, A., Elci, M., \& Tamer Toklu, I. (2016b). Effects of Occupational Health and Safety Practices on Organizational Commitment, Work Alienation and Job Performance: Using the PLS-SEM Approach. International Journal of Business and Management, 11(5), 146. https://doi.org/10.5539/ijbm.v11n5p146

Liu, S., Gyabeng, E., Joshua Atteh Sewu, G., Nkrumah, N. K., \& Dartey, B. (2019). Occupational Health and Safety and Turnover Intention in the Ghanaian Power Industry: The Mediating Effect of Organizational Commitment. BioMed Research International, 2019. https://doi.org/10.1155/2019/3273045

Malik, M. I., Gomez, S. F., \& Ali, M. (2011). A Study of Work Environment and Employees' Performance in Pakistan. African Journal of Business Management, 5(34), 13227-13232. https://doi.org/10.5897/ajbm11.1502

Maryjoan, I., \& Tom, E. E. (2016). Effects of Industrial Safety and Health on Employees' Job Performance in Selected Cement Companies in Cross River State, Nigeria. International Journal of Business and Management Review, 4(3), 49-56. www.eajournals.org

Mwangi, J. W., \& Waiganjo, E. (2017). Influence of Occupational Health and Safety on Employees' Performance in the Flower Industry in Kenya: a Case Study of Penta Flowers Limited. Journal of Business \& Change Management, 4(3), 191-208.

Nderi, F. W., \& Kirai, M. (2017). Influence of Work Environment on Employee Performance in the Security Sector in Kenya: a Case of Kenya Police Service Nairobi City Country. Journal of Business \& Change Management, 4(4), 1010-1036. https://doi.org/10.1016/j.talanta.2003.12.004

Ollukkaran, M. B. A., \& Gunaseelan, D. R. (2012). A Study on the Impact of Work Environment on Employee Performance. Namex International Journal of Management Research, 2(2).

Özer, Ö., Uğurluoğlu, Ö., Saygıll, M., \& Sonğur, C. (2019). The Impact of Work Alienation on Organizational Health: A Field Study in Health Sector. International Journal of Healthcare Management. https://doi.org/10.1080/20479700.2017.1312804

Putri, D. O., Triatmanto, B., \& Setiyadi, S. (2017). The Effect of Occupational Health and Safety, Work Environment and Discipline on Employee Performance in a Consumer Goods Company. IOP Conference Series: Materials Science and Engineering, 337(1). https://doi.org/10.1088/1757899X/337/1/012036

Qader, A. A.-. (2017). Work Alienation and Its Influence on Employees' Performance Among a Sample of the Industrial Sector in Jordan. Journal of Resources Development and Management, 37, 82-89.

Riaz, A., Shoaib, U., \& Shahzad, M. (2017). Workplace Design and Employee's Performance and Health in Software Industry of Pakistan. International Journal of Advanced Computer Science and Applications, 8(5), 542-548. https://doi.org/10.14569/ijacsa.2017.080567

Saeed, I., Fatima, T., \& Junaid, M. (2018). Impact of Organization Cynicism on Work Outcomes: Mediating Role of Work Alienation. NICE Research Journal, 122-138. https://doi.org/10.51239/nrjss.v0i0.8

Tengilimoglu, D., Celik, E., \& Guzel, A. (2016). The Effect of Safety Culture on Safety Performance: Intermediary Role of Job Satisfaction. British Journal of Economics, Management \& Trade, 15(3), 1-12. https://doi.org/10.9734/bjemt/2016/29975

Tomo, A., \& Todisco, L. (2018). Enhancing Employees ' Performance through Organizational Care Policies in the Health Care Context. Public Administration Research, 7(1), 5-19. https://doi.org/10.5539/par.v7n1p5

Tuwai, B. B., Kamau, C., \& Kuria, S. (2015). Effect of Corporate Wellbeing Practices On Employees' Performance among Commercial Banks in Kenya. International Journal of Scientific and Research Publications, 5(5). www.ijsrp.org

Ulutasdemir, N., Duran, M., \& Balsak, H. (2018). Effect of Safety of Health Professionals working in a Private Hospital on their Personal and Social Performances. June.

Umugwaneza, C., Nkechi, I. E., \& Mugabe, J. B. (2019). Effect of Workplace Safety and Health Practices on Employee Commitment and Performance in Steel Manufacturing Companies in Rwanda. 4(5), 111. 
Wambui, M. L., Cherotich, C., Emily, T., \& Dave, B. (2017). Effects of Work life Balance on Employees' Performance in Institutions of Higher Learning. A Case Study of Kabarak University. Kabarak j. res. innov. Kabarak Journal of Research \& Innovation, 4(2), 60-79.

Yusuf, R. M., Eliyana, A., \& Novita Sari, O. (2012). The Influence of Occupational Safety and Health on Performance with Job Satisfaction as Intervening Variables (Study on the Production Employees in PT. Mahakarya Rotanindo, Gresik). American Journal of Economics. https://doi.org/10.5923/j.economics.20120001.30 